\title{
Adrenal Contribution to Polycystic Ovary Syndrome
}

\author{
H.A. Bayoumy A.N. Alothman \\ Department of Endocrinology, Al-Sabah Hospital, Ministry of Health, Kuwait
}

\section{Key Words}

Polycystic ovary syndrome $\cdot$ Hyperandrogenaemia . Adrenal steroidogenesis

\begin{abstract}
Objective: To examine further the dynamics of adrenal steroidogenesis in selected groups of patients with polycystic ovary syndrome (PCOS) compared to normal ovulatory women of the same age. Materials and Methods: Serum cortisol, testosterone, dehydroepiandrosterone sulphate (DHEAS), androstenedione (A), luteinizing hormone (LH), follicle-stimulating hormone, prolactin, 17hydroxyprogesterone (17-OHP) and sex hormone-binding globulin (SHBG) were measured in the early follicular phase of the period. In addition, 2-day dexamethasone suppression and short adrenotropic hormone (ACTH) stimulation tests were performed for the study group and controls. Results: Serum testosterone (4.3 \pm $1.8 \mathrm{nmol} / \mathrm{l})$, LH $(7.6 \pm 1.9 \mathrm{IU} / \mathrm{l})$, and $17-\mathrm{OHP}(4.7 \pm$ $2.3 \mathrm{nmol} / \mathrm{l})$ were higher while SHBG $(24.7 \pm 14.2 \mathrm{nmol} / \mathrm{l})$ was lower in patients than the control. Testosterone was significantly suppressed after dexamethasone suppression test while the level of 17-OHP increased significantly in patients more than the control after $60 \mathrm{~min}$ of $\mathrm{ACTH}$ stimulation. In the PCOS, the ratio of 17-OHP/A showed a significant increase after ACTH stimulation while that of DHEAS/A decreased when compared to controls. Con-
\end{abstract}

clusion: The study suggests a contribution of adrenal cytochrome P-450C dysregulation in PCOS. This suggestion could lead to another method of treating some PCOS patients when the usual anti-androgens might not be fully effective in controlling most of the symptoms.

Copyright $\odot 2002$ S. Karger AG, Basel

\section{Introduction}

Polycystic ovary syndrome (PCOS) is one of the most common endocrinopathies in women of reproductive age. According to the initial description, the diagnosis of PCOS is based on clinical symptoms (oligomenorrhoea, infertility, hirsutism, and obesity) in the presence of polycystic ovaries verified sonographically or histologically on laparotomy [1].

The syndrome is endocrinologically heterogeneous. It is characterized variably by hyperandrogenism and inappropriate gonadotrophin secretion. However, the ultimate pathogenesis of PCOS has remained obscure [2]. Although the role of the ovary in the pathogenesis of hyperandrogenism seems to be important, there are several indications of a disturbed adrenocortical activity in these patients [3], but the regulatory mechanism(s) of adrenal androgen production still need(s) to be thorougly investigated [4]. It is also known that the pattern of polycystic ovaries, which is very common in this group, does

\begin{tabular}{ll}
\hline KARGER & ( ) 2001 S. Karger AG, Basel \\
1011-7571/01/0103-0151\$17.50/0 \\
$\begin{array}{l}\text { Fax+41613061234 } \\
\text { www.karger.com }\end{array}$ & $\begin{array}{l}\text { Accessible online at: } \\
\text { www.karger.com/journals/mpp }\end{array}$
\end{tabular}

H.A. Bayoumy
Department of Endocrinology
Al-Sabah Hospital
PO Box 4078, 13041 Safat (Kuwait)
E-Mail bayoumy22@hotmail.com 
not necessarily indicate an ovarian origin of the androgen excess but may be secondary to abnormal adrenal function [5].

Two types of adrenal abnormalities have been described in PCOS: adrenal enzyme dysfunction and adrenal androgen hyperresponsiveness to ACTH. Mild adrenal $3 \beta$-hydroxysteroid dehydrogenase (3 $\beta$-HSD) deficiency has been demonstrated with persistence of adrenal androgen hyperresponsiveness to ACTH [6]. More recently, it has been shown that in PCOS patients, oestrogen may induce adrenal androgen hyperresponsiveness to ACTH [7]. These findings in part suggest an impact of ovarian steroids on adrenal steroidogenesis. Nevertheless, there are also compelling indications that the ovary may modulate adrenal androgen secretion. Ovarian failure accelerates the age-related decline in adrenal androgens [8].

It has been observed in clinical practice that these patients are not always completely cured when given antiandrogen treatment if this androgen source is only ovarian. There is therefore the possibility that another source of androgen (adrenal source) could associate and/or contribute to the situation of hyperandrogenaemia and is present in this category of patients.

The aim of this study is to test the adrenal androgen production contributing to the hyperandrogenic state in patients with PCOS.

\section{Materials and Methods}

Twenty-four selected women attending the Endocrine Unit, AlSabah Hospital, with hirsutism (Ferriman-Gallwey score >10) and/ or irregular cycles participated in this study. All of them were in the fertile age, none were obese, hypertensive, or diabetic with any history of hepatic or renal trouble. They also had elevated serum luteinizing hormone ( $\mathrm{LH})$, elevated $\mathrm{LH}$ follicle-stimulating hormone (FSH) coefficient ratio, abnormally high androgen profile, including low sex hormone-binding globulin (SHBG), and, consequently, a high free androgen index. Pelvic ultrasonography was done for all 24 patients. Thirteen normal, healthy women, age-matched, regularly menstruating with normal ovarian morphological appearance on abdominopelvic sonography were the controls.

The women with PCOS were examined during their oligomenorrhoeic periods and the control women in the early follicular days of the cycle (days 3-6). Samples were taken during the oligomenorrhoeic phase for cases of PCOS and during the early follicular phase of controls. All serum samples were kept frozen at $-20^{\circ} \mathrm{C}$ until analysed.

\section{Assay of Basal Hormone Level}

The serum samples for cortisol, testosterone, dehydroepiandrosterone sulphate (DHEAS), androstenedione (A), LH, FSH, prolactin, 17-hydroxyprogesterone (17-OHP) and SHBG were measured using the ELISA technique.
Table 1. Anthropometric and clinical data of the studied patients and controls

\begin{tabular}{lcrl}
\hline & $\begin{array}{l}\text { Patients } \\
(\mathrm{n}=24)\end{array}$ & $\begin{array}{l}\text { Controls } \\
(\mathrm{n}=13)\end{array}$ & $\mathrm{p}$ \\
\hline Age, years & $25.5 \pm 4.5$ & $27.2 \pm 3.9$ & 0.3 \\
Weight, kg & $60.3 \pm 2$ & $56.4 \pm 3.6$ & $0.00^{*}$ \\
Height, cm & $157.9 \pm 2.5$ & $159.4 \pm 1.3$ & 0.06 \\
BMI, $\mathrm{kg} / \mathrm{m}^{2}$ & $23.1 \pm 1.3$ & $22.6 \pm 0.8$ & 0.3 \\
\hline
\end{tabular}

$* \mathrm{p}<0.001$

Table 2. Basal hormonal profiles of PCOS patients and controls

\begin{tabular}{lccl}
\hline Basal hormone profile & $\begin{array}{c}\text { Patients } \\
(\mathrm{n}=24)\end{array}$ & $\begin{array}{c}\text { Controls } \\
(\mathrm{n}=13)\end{array}$ & $\mathrm{p}$ \\
\hline $\mathrm{LH}, \mathrm{IU} / \mathrm{l}$ & $7.6 \pm 1.9$ & $3.8 \pm 0.9$ & $0.00^{* *}$ \\
FSH, IU/1 & $5.4 \pm 1.2$ & $6.6 \pm 0.8$ & $0.005^{* *}$ \\
Prolactin, $\mathrm{mIU} / \mathrm{l}$ & $283 \pm 58$ & $176 \pm 34$ & $0.00^{* *}$ \\
Testosterone, nmol/1 & $4.3 \pm 1.8$ & $1.1 \pm 0.2$ & $0.00^{* *}$ \\
Cortisol, $\mathrm{nmol} / \mathrm{l}$ & $335 \pm 170$ & $220 \pm 35$ & $0.02^{* *}$ \\
17-OHP, nmol/1 & $4.7 \pm 2.3$ & $1.8 \pm 0.4$ & $0.00^{* *}$ \\
DHEAS, $\mu \mathrm{mol} / 1$ & $8.9 \pm 6.5$ & $2.5 \pm 0.5$ & $0.001^{* *}$ \\
A, nmol/I/A & $4.5 \pm 1.5$ & $1.7 \pm 0.9$ & $0.00^{* *}$ \\
SHBG, nmol/1 & $24.7 \pm 14.2$ & $109.7 \pm 18.8$ & $0.00^{*}$ \\
\hline
\end{tabular}

$* \mathrm{p}<0.05, * * \mathrm{p}<0.005$

\section{Dynamic Adrenal Studies}

Dexamethasone Suppression. Dexamethasone suppression was implemented in an outpatient setting by giving $2 \mathrm{mg}$ of the drug orally daily $(0.5 \mathrm{mg}$ every $6 \mathrm{~h})$ for 2 days. Serum samples for testosterone, cortisol, and DHEAS measurements were taken on the morning before the test and on the 3rd day, and assayed using ELISA technique.

ACTH Stimulation. The ACTH test was carried out by giving $250 \mu \mathrm{g}$ as an intravenous bolus in the morning after an overnight fast on the 1st day of hospitalization. Blood samples for cortisol, DHEAS, and $\mathrm{A}$ were taken at 0 and $60 \mathrm{~min}$ and assayed as previously described.

\section{Statistical Analysis}

The data were analysed using the SPSS software packages for Windows version 8 . The mean and standard deviation (SD) were calculated of both patients and controls. Independent samples t test was used to test the difference between two categorical variables. The calculated ratios of 17-OHP/A and DHEAS/A were compared to ascertain their biological significance. 
Table 3. Response of serum cortisol, DHEAS, and testosterone to dexamethasone suppression test

\begin{tabular}{|c|c|c|c|c|c|c|}
\hline \multirow[t]{2}{*}{ Steroids } & \multicolumn{2}{|c|}{ Patients $(n=24)$} & \multicolumn{2}{|c|}{ Controls $(n=13)$} & \multicolumn{2}{|l|}{$\mathrm{p}$} \\
\hline & basal & after & basal & after & basal & after \\
\hline Cortisol, nmol/1 & $170 \pm 335$ & $26 \pm 92$ & $35 \pm 220$ & $4 \pm 16$ & $0.02 *$ & $0.00^{* *}$ \\
\hline DHEAS, $\mu \mathrm{mol} / 1$ & $6.5 \pm 8.9$ & $1.7 \pm 3.4$ & $0.5 \pm 2.5$ & $0.1 \pm 1$ & $0.001 * *$ & $0.00 * *$ \\
\hline Testosterone, nmol/1 & $1.8 \pm 4.3$ & $0.6 \pm 1.6$ & $0.2 \pm 1.1$ & $0.3 \pm 0.8$ & $0.000^{* *}$ & $0.00 * *$ \\
\hline
\end{tabular}

$* \mathrm{p}<0.05, * * \mathrm{p}<0.001$
Table 4. Response of cortisol, A, DHEAS and 17-OHP to ACTH stimulation

\begin{tabular}{|c|c|c|c|c|c|c|}
\hline \multirow[t]{2}{*}{ Steroids } & \multicolumn{2}{|c|}{ Patients $(n=24)$} & \multicolumn{2}{|c|}{ Controls $(\mathrm{n}=13)$} & \multicolumn{2}{|l|}{$\mathrm{p}$} \\
\hline & basal & after & basal & after & basal & after \\
\hline Cortisol, nmol/1 & $170 \pm 335$ & $90 \pm 347$ & $35 \pm 220$ & $79 \pm 396$ & $0.02 *$ & 0.11 \\
\hline 17-OHP, nmol/1 & $2.3 \pm 4.7$ & $4.7 \pm 10$ & $0.4 \pm 1.8$ & $0.2 \pm 1.8$ & $0.00^{* *}$ & $0.00 * *$ \\
\hline DHEAS, $\mu \mathrm{mol} / \mathrm{l}$ & $6.5 \pm 8.9$ & $6.3 \pm 11.4$ & $0.5 \pm 2.5$ & $0.5 \pm 2.6$ & $0.001 * *$ & $0.00 * *$ \\
\hline $\mathrm{A}, \mathrm{nmol} / 1$ & $1.5 \pm 4.3$ & $2.7 \pm 6.7$ & $0.9 \pm 1.7$ & $0.7 \pm 2.2$ & $0.00 * *$ & $0.00 * *$ \\
\hline
\end{tabular}

$* \mathrm{p}<0.05, * * \mathrm{p}<0.001$.

\section{Results}

All 24 patients showed typical ultrasonographic features either in a single ovary or in both ovaries of either enlarged or normal-sized ovaries with multiple $(>10 \mathrm{~mm})$ or small $(2-20 \mathrm{~mm})$ subcortical follicles. The age, height, weight, and body mass index (BMI) of patients and controls are given in table 1 . There is no statistically significant difference between age, height, BMI of the patients and the controls, but there was a statistically significant difference between the weight of the patients and controls. The basal hormone profiles of both patients and controls are given in table 2. The patients with PCOS have statistically significant high serum LH, FSH, testosterone, cortisol, 17-OHP, DHEAS, and A profiles. SHBG serum level of the patients was lower than that of the controls. Both testosterone and DHEAS were suppressed to a normal level in patients by dexamethasone, while serum cortisol was suppressed to below normal level (nmol/l). In controls, dexamethasone had a suppression effect on cortisol and DHEAS but no effect on testosterone. Table 3 reveals that the suppression effect of dexamethasone was more significant on patients with PCOS than controls $(\mathrm{p}<$ 0.001). The effect of ACTH stimulation is given in table 4 . $\mathrm{ACTH}$ increased the levels of all the hormones in both
Table 5. Ratios of 17-OHP/A and DHEAS/A ratio after ACTH stimulation test

\begin{tabular}{lllllll}
\hline \multirow{2}{*}{ Ratio } & \multicolumn{2}{l}{ Patients $(\mathrm{n}=24)$} & $\mathrm{p}$ & & \multicolumn{2}{c}{ Controls $(\mathrm{n}=13)$} \\
\cline { 2 - 3 } \cline { 6 - 7 } & before & after & & & before & after \\
\hline 17-OHP/A & $0.3 \pm 0.8$ & $0.4 \pm 1.4$ & $0.004^{*}$ & $0.4 \pm 1.1$ & $0.2 \pm 0.9$ \\
DHEAS/A & $2.2 \pm 2.3$ & $1.5 \pm 2$ & 0.096 & & $0.7 \pm 1.5$ & $0.9 \pm 1.2$
\end{tabular}

$* \mathrm{p}<0.005$

patients and controls. The increase in the level of the hormones was most pronounced in 17-OHP and DHEAS of PCOS patients.

\section{Steroid Ratios}

The ratios of 17-OHP to A and DHEAS to A for both patients and controls are given in table 5. The ratio of 17 OHP to A in PCOS patients increased while that of DHEAS to A did not change after ACTH stimulation. Both ratios tended to decrease in controls after ACTH stimulation. 


\section{Discussion}

In this study, adrenal and ovarian androgen secretions were assessed in 24 women with hyperandrogenaemia and PCOS. They had typical hormonal features of PCOS. In all cases, characteristic ultrasonic findings of PCOS were detected compared to the 13 normal controls of matched age. Neoplastic origin of the androgen hypersecretion or late onset of enzyme deficiency reported to occur frequently in such cases [12] was excluded clinically from this study.

Basically, in the PCOS group there was the usual gonadotrophin pattern characteristic of this group as reported by many investigators $[13,14]$. The serum concentration of testosterone and 17-OHP was significantly higher in patients with PCOS than in the control group compared to other weak androgens from adrenal sources such as DHEAS and rostenedione. Therefore, it is suggested that partial enzymatic dysregulation at the adrenal level could be a contributing factor to the increased androgen levels in the PCOS patients.

Dexamethasone suppression test showed clearly suppressed testosterone in the PCOS patients, suggesting the association of adrenal androgen drive or hyperresponsiveness to ACTH. Moreover, it has recently been shown that in PCOS, oestrogen may also induce adrenal androgen overstimulation to ACTH, which could partially explain the influence of ovarian steroid on adrenal androgen synthesis [7, 15]. In ACTH stimulation test, the PCOS patients demonstrated significantly higher basal and stimulated levels of 17-OHP, DHEAS, and androstenedione in comparison to controls.

These two dynamic adrenal test profiles led to the speculation that there could be a partial contribution of weak adrenal androgens to the androgen pool in PCOS patients, which might be attributed to adrenal enzymatic dysfunction. However, there is a lack of consensus in previous studies regarding the role of adrenal enzyme dysfunction as a contributor to adrenal androgen excess in PCOS [16, 17]. Dysregulation of the cytochrome P-450 C17 hydroxylase, 17, 20 lyase enzyme complex (cytochrome P-450 C17) has been proposed as a possible mechanism for adrenal hyperandrogenism in this subgroup of patients. This hypothesis is supported by and consistent with previous reports [18, 19].

The ratios of 17-OHP/A and DHEAS/A were taken as an index for the activity of cytochrome P-450 C17 and $3 \beta$-HSD enzymes in ACTH stimulation test at the basal level and after $60 \mathrm{~min}$ [20]. Therefore, they can be used as indirect evidence of the possible dysregulation of adrenal enzymes which may be a contributing factor in these patients.

In the studied subgroup of PCOS, the findings revealed a significant increase in 17-OHP/A after the stimulation test, whereas this increase was not significant in the DHEAS/A ratio. However, these ratios decreased in the control group. These results indicate that the adrenal gland contributes to hyperandrogenaemia in this subgroup of PCOS through a functional impairment of its cytochrome P-450 C17 enzyme.

\section{Conclusion}

This study provides new evidence of the importance of adrenal glands as a sharing source for hyperandrogenaemia in some cases of PCOS. The results could lead to a new diagnostic method for identifying this subgroup of PCOS with functional intra-adrenal enzymatic impairment. Such a diagnosis would be helpful in planning successful treatment protocols. More research is needed in this area to confirm this modified mechanism of adrenal study in patients with PCOS.

\section{References}

1 Stein IF, Leventhal ML: Amenorrhea associated with bilateral polycystic ovaries. Am J Obstet Gynecol 1935;29:181-191.

2 Yen SSC: Chronic anovulation caused by peripheral endocrine disorders; in Yen SC, Barbieri RL, Jaffe RB, Bralow L (eds): Reproductive Endocrinology. Philadelphia, Saunders, 1991, pp 576-630.
3 Turner EI, Watson MJ, Perry LA, White MC: Investigation of adrenal function in women with oligomenorrhoea and hirsutism (clinic PCOS) from the north-east of England using an adrenal stimulation test. Clin Endocrinol (Oxf) 1992;36:389-397.

4 Rodin A, Thakkar H, Taylor N, Clayton R: Hyperandrogenism in polycystic ovary syndrome: Evidence of dysregulation of 11 betahydroxysteroid dehydrogenase. N Engl J Med 1994;330:460-465.
5 O'Driscoll JB, Mamtora H, Higginson J, Pollock A, Kane J, Anderson DC: A prospective study of the prevalence of clear-cut endocrine disorders and polycystic ovaries in 350 patients presenting with hirsutism or androgenic alopecia. Clin Endocrinol (Oxf) 1994;41:231-236.

6 Gonzalez F, Hatala DA, Speroff L: Adrenal and ovarian steroid hormone responses to gonadotropin-releasing hormone agonist treatment in polycystic ovary syndrome. Am J Obstet Gynecol 1991;165:535-545. 
7 Ditkoff EC, Fruzzetti F, Chang L, Stancyzk FZ, Lobo RA: The impact of estrogen on adrenal androgen sensitivity and secretion in polycystic ovary syndrome. J Clin Endocrinol Metab 1995;80:603-607.

8 Orentreich N, Brind JL, Vogelman JH, Andres $\mathrm{R}$, Baldwin $\mathrm{H}$ : Long-term longitudinal measurements of plasma dehydroepiandrosterone sulfate in normal men. J Clin Endocrinol Metab 1992;75:1002-1004.

9 Robinson S, Rodin DA, Deacon A, Wheeler MJ, Clayton RN: Which hormone tests for the diagnosis of polycystic ovary syndrome? $\mathrm{Br} \mathrm{J}$ Obstet Gynaecol 1992;99:232-238.

10 Abdel Gadir A, Khatim MS, Mowafi RS, Alnaser HM, Mubarib NS, Shaw RW: Implications of ultrasonically diagnosed polycystic ovaries. I. Correlations with basal hormonal profiles. Hum Reprod 1992;7:453-457.

11 Cohran WG: Sampling Techniques. New York, Wiley \& Sons, 1977, pp 180-183.
12 Mathieson $\mathrm{H}$, Couzinet B, Wekstein-Noel S, Naboul K, Turpin G, Schaison G: The incidence of late-onset congenital adrenal hyperplasia due to 3 beta-hydroxysteroid dehydrogenase deficiency among hirsute women. Clin Endocrinol (Oxf) 1992;36:383-388.

13 Keettel WC, Bradbury JT, Stoddard FJ: Observations of PCO syndrome. Am J Obstet Gynecol 1957;73:954-965.

14 Yen SS, Vela P, Rankin J: Inappropriate secretion of follicle-stimulating hormone and luteinizing hormone in polycystic ovarian disease. $\mathrm{J}$ Clin Endocrinol Metab 1970;30:435-442.

15 Lachelin GC, Barnett M, Hopper BR, Brink G, Yen SS: Adrenal function in normal women and women with polycystic ovary syndrome. J Clin Endocrinol Metab 1979;49:892-898.

16 Lobo RA, Goebelsmann U: Evidence for reduced 3 beta-ol-hydroxysteroid dehydrogenase activity in some hirsute women thought to have polycystic ovary syndrome. J Clin Endocrinol Metab 1981;53:394-400.
17 Siegel SF, Finegold DN, Lanes R, Lee PA: ACTH stimulation tests and plasma dehydroepiandrosterone sulfate levels in women with hirsutism. N Engl J Med 1990;323:843-854.

18 Gonzalez F, Speroff L: Adrenal morphologic considerations in polycystic ovary syndrome: A review. Obstet Gynecol Surv 1990;45:491508.

19 Rosenfield RL, Barnes RB, Cara JF, Lucky AW: Dysregulation of cytochrome P450c17 alpha as a cause of polycystic ovary syndrome. Fertil Steril 1990;53:785-791.

20 Pang SY, Lerner AJ, Stoner E, Levine LS, Oberfield SE, Engel I, New MI: Late-onset adrenal steroid 3 beta-hydroxysteroid dehydrogenase deficiency. I. A cause of hirsutism in pubertal and postpubertal women. J Clin Endocrinol Metab 1985;60:428-439. 